\title{
Fatores intervenientes do desmame precoce durante o aleitamento materno exclusivo
}

\author{
Intervening factors of early weaning during exclusive breastfeeding
}

Factores que intervienen en el destete temprano durante la lactancia materna exclusiva

Shelda Cunha de Araújo ${ }^{1 *}$, Alane Dantas Araújo de Souza ${ }^{1}$, Aiara Nascimento Amaral Bomfim², Josely Bruce dos Santos ${ }^{2}$.

\section{RESUMO}

Objetivo: Identificar os fatores que interferem no desmame precoce durante o aleitamento materno exclusivo. Métodos: Trata-se de uma revisão integrativa, realizada no período de abril a outubro de 2020, utilizando um corte temporal de 10 anos, a fim de coletar informações das bases de dados Biblioteca Virtual Scientific Electronic Library Online (SciELO), Biblioteca Virtual em Saúde (BVS) e PubMed, com um quantitativo de 10 artigos utilizados para amostra final. A sistematização dos dados foi realizada pelo referencial teórico de Bardin. Resultados: Foram observados diversos fatores que intervêm no desmame, dentre eles os socioeconômicos, culturais, intercorrências mamárias, retorno da genitora ao trabalho, baixa escolaridade, uso de chupetas e ausência de orientação são os mais comumente encontrados. Considerações finais: A perpetuação do desmame é visto como um problema que interfere diretamente nas taxas de aleitamento materno exclusivo, fazendo necessária a atuação da enfermagem no acompanhamento nas e orientações às puérperas para promoção da amamentação.

Palavras-chave: Amamentação, Desmame precoce, Enfermagem.

\begin{abstract}
Objective: To identify the factors that interfere with early weaning during exclusive breastfeeding. Methods: This is an integrative review, carried out from April to October 2020, using a 10-year time cut, in order to collect information from the databases Virtual Library Scientific Electronic Library Online (SciELO), Virtual Library in Saúde (BVS) and PubMed, with a quantity of 10 articles used for the final sample. The systematization of the data was carried out using Bardin's theoretical framework. Results: Several factors that intervene in weaning were observed, including socioeconomic, cultural, breast complications, mother's return to work, low education, use of pacifiers and lack of guidance are the most commonly found. Final considerations: The perpetuation of weaning is seen as a problem that directly interferes in the rates of exclusive breastfeeding, making it necessary for nursing to follow up on and guide mothers to promote breastfeeding.
\end{abstract}

Keywords: Breastfeeding, Early weaning, Nursing.

RESUMEN

Objetivo: Identificar los factores que interfieren con el destete temprano durante la lactancia materna exclusiva. Métodos: Se trata de una revisión integradora, realizada de abril a octubre de 2020, utilizando un plazo de 10 años para reunir información de las bases de datos de la Biblioteca Electrónica Científica Virtual en Línea (SciELO), la Biblioteca Virtual de Salud (BVS) y PubMed, con un cuantitativo de 10 artículos utilizados para la muestra final. Los datos fueron sistematizados por la referencia teórica de Bardin. Resultados: Se observaron varios factores que intervienen en el destete, entre ellos los socioeconómicos, culturales, las intercurrencias mamarias, regreso de la mujer al trabajo, baja escolaridad, uso de chupetes y la falta de orientación son los más comunes. Consideraciones finales: La perpetuación del destete se ve como un problema que interfiere directamente en las tasas de lactancia materna exclusiva, por lo que es necesario que la lactancia dé seguimiento y oriente a las madres para promover la lactancia materna.

Palabras clave: Lactancia materna, Destete temprano, Enfermería.

${ }^{1}$ Centro Universitário Jorge Amado (UNIJORGE), Salvador - BA. *E-mail: shelda602@gmail.com

2 Universidade Federal da Bahia (UFBA), Salvador - BA.

Departamento de Iniciação Científica UNIJORGE

SUBMETIDO EM: 3/2021

ACEITO EM: $3 / 2021$

PUBLICADO EM: 4/2021

REAS | Vol. 13(4) | DOI: https://doi.org/10.25248/REAS.e6882.2021

Página 1 de 8 


\section{INTRODUÇÃO}

Amamentar é um instinto natural, que fornece a nutrição adequada ao bebê desde o seu primeiro dia de vida, supre necessidades fisiológicas, afetivas e auxilia no desenvolvimento físico e mental do neonato, pois o leite materno possui nutrientes essenciais como proteínas, vitaminas e sais minerais. Embora seja um processo fisiológico, é comum às genitoras, que 0 ato de amamentar decorra de dificuldades que culminam no processo de interrupção do aleitamento materno exclusivo. O desmame precoce ocorre quando há a interrupção do aleitamento materno exclusivo antes dos seus meses de vida da criança, ocasionada por diversos fatores. A enfermagem tem o importante papel na intervenção do desmame precoce, devendo estar capacitada e comprometida, tem sua atuação desde o pré-natal até o puerpério, transmite orientações de acordo com as necessidades (MARTINS MZO e SANTANA LS, 2013; OLIVEIRA CS, et al., 2015; MONTESCHIO CAC, et al., 2015).

O lactente em seus primeiros meses de vida está numa fase de adaptação à vida extrauterina, possuindo maiores necessidades por não estar mais ligado à sua genitora pelo cordão umbilical. $\mathrm{O}$ aleitamento materno exclusivo (AME) tem grande relevância a respeito da qualidade de vida da criança, auxilia no desenvolvimento e no fortalecimento do sistema imunológico ainda em formação, além de fortalecer o vínculo mãe-bebê. Dessa forma, a amamentação exclusiva é reconhecida como uma estratégia para reduzir as taxas de morbimortalidade infantil (MARTINS MZO e SANTANA LS, 2013; BRASIL, 2015).

O aleitamento materno tem repercussões também na saúde da nutriz, evitando o surgimento do câncer de mama, e até mesmo podendo reduzir cerca de 20 mil mortes anuais decorrentes desse problema. Quanto mais tempo a nutriz prolongar o aleitamento, menos chance ela terá de desenvolver o câncer. Além disso, também protege contra câncer de ovário, contribui para o retorno ao peso pré-gravídico, auxilia no processo de involução uterina e cicatrização, tendo assim menos chance de desenvolver hemorragia pós parto (UNICEF, 2019; BRASIL, 2015).

Segundo a Organização Pan-Americana de Saúde (2017), a primeira mamada deve acontecer na primeira hora de vida do neonato, porém na América Latina, cerca de $52 \%$ não são amamentados nesse período ideal. Recomenda-se também que a amamentação seja mantida até os dois anos de idade, porém até os 6 meses de maneira exclusiva. Apesar da América Latina estar entre as regiões de maior taxa de adesão do AME, esses valores não chegam a 50\%. Aqueles lactentes que são amamentados conforme o recomendado, possuem maior coeficiente intelectual, estando associada a melhores condições em questão de renda e qualidade de vida quando adultos.

O desmame geralmente vem acompanhado de uma introdução alimentar precoce ou do uso de leites artificiais, o que ocasiona problemas à saúde do bebê. A interrupção do aleitamento materno exclusivo é causa de muitos prejuízos para a saúde infantil, como por exemplo, dificuldades no desenvolvimento físico e psíquico, bem como no aumento da suscetibilidade a outras doenças, resultando numa maior incidência no aumento da taxa de mortalidade (SILVA ACR, et al., 2019)

O desempenho da enfermagem frente a promoção e a orientação da amamentação é justamente reduzir as taxas de desmamem precoce e consequentemente aumentar as taxas de aleitamento materno exclusivo. Intervenções são feitas através da elaboração de estratégias e medidas, com atuações de maneira interdisciplinar, foco na promoção do aleitamento e na prevenção de intercorrências. O profissional de saúde deve cativar essas mulheres, com um atendimento acolhedor e de escuta ativa, para que as orientações sejam seguidas e efetivadas (FLORINDO AKF, et al., 2018).

A Organização Pan-Americana da Saúde (2017), insiste para que os governos promovam a causa, que sejam criados mais hospitais amigos das crianças, apliquem e reforcem políticas a respeito do direito à maternidade que estejam também relacionadas a direitos trabalhistas. O Ministério da Saúde (2017) discute e desenvolve ações para reduzir a taxa de desmame precoce, incentivar e informar a população sobre a importância do aleitamento materno exclusivo, através de estratégias como a identificação dos problemas mais comuns e como resolvê-los.

Diante do exposto, esse estudo tem como objetivo identificar quais são os fatores intervenientes para a ocorrência do desmame precoce durante o aleitamento materno exclusivo. Através dessa revisão poderá aprimorar conhecimento e disseminá-lo para que estratégias especificas possam contribuir de fato para a mitigação dessa problemática. 


\section{MÉTODOS}

Refere-se a um estudo bibliográfico através do método de revisão integrativa, com a finalidade de identificar os fatores que levam ao desmame precoce. A revisão integrativa possibilita de maneira ampla ampliar conhecimento através da capacidade de sistematização do científico fazendo a inclusão de diversos artigos a respeito do tema, colhendo pontos importantes e aumentando a validade das informações (8). Foi elaborado com base em etapas, sendo elas a busca na literatura, coleta de dados, análise crítica dos estudos incluídos, discussão dos resultados e apresentação da revisão integrativa (SOUSA LMM, et al., 2017)

A pesquisa foi realizada respeitando a legislação sobre direitos autorais, regidos pelo decreto $n^{\circ} 9.574$, de 22 de novembro de 2018. As plataformas de artigos científicos utilizadas para busca foram conduzidas pela BVS, SciELO e PubMed. O recorte temporal utilizado foi de 2011 a 2020. Foram utilizados os Descritores em Ciências da Saúde (DeCS): Aleitamento materno; desmame precoce; Enfermagem;

Estabeleceu-se a seguinte questão de pesquisa: "quais os fatores intervenientes no desmame precoce?" Os conteúdos encontrados supriram os seguintes critérios de inclusão: abordagem dentro da temática, artigos publicados na íntegra, período de publicação de até 10 anos atrás até os dias atuais, disponível em português / inglês / espanhol, resultados de pesquisas de campo e artigos disponíveis na íntegra. Os critérios de exclusão utilizados foram: artigos fora da abordagem da temática, revisões de literatura, teses e dissertações.

Foi utilizado um instrumento de análise para organização de resultados, com uma tabela compondo os seguintes elementos: artigo; periódico; ano; identificação dos autores; objetivo; resultados e natureza do estudo. A sistematização dos dados foi realizada pelo referencial teórico de Bardin, na modalidade de Análise Categorial Temática. Após a exploração do material as categorias foram elaboradas, reunindo informações que auxiliem a compreensão através de recortes, enumerações, a fim de reunir unidades de registros de diferentes temáticas que possuam vínculo com o tema principal abordado, até ter sido alcançado conteúdo suficiente para atingir o objetivo desse estudo (BARDIN L, 2016).

As pesquisas reuniram 384 documentos no total, onde apenas 24 foram selecionados e desses, 10 foram utilizados. Ao fim da leitura dos artigos utilizados, foram analisados e discutidos para apresentar os resultados e a conclusão geral da pesquisa (Figura 1).

Figura 1 - Representação do delineado do estudo.

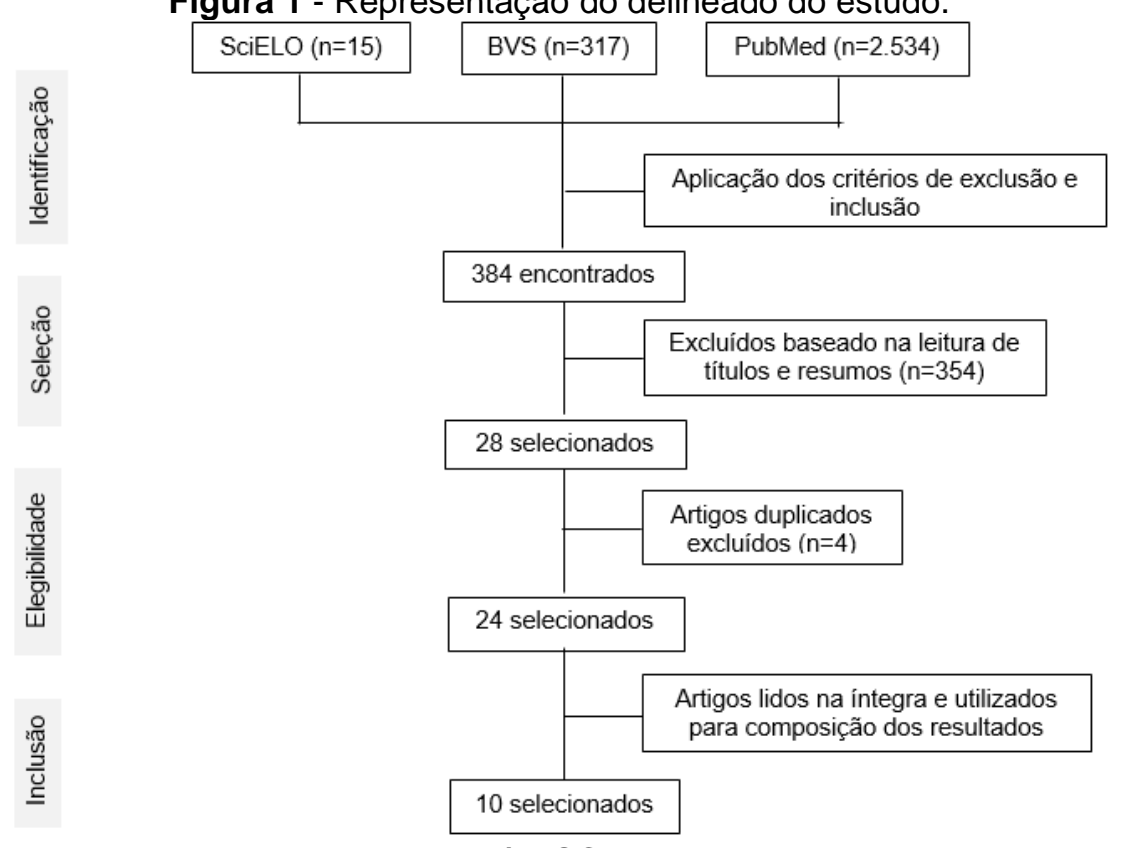

\section{RESULTADOS}

Fonte: Araújo SC, et al., 2021

Com a exploração dos 10 artigos selecionados para amostra, sendo 4 da SciELO, 5 da BVS e 1 da PubMed, foi possível observar que os estudos são de grande maioria de natureza descritiva, quantitativa e exploratória, publicados em revistas eletrônicas brasileiras e com fatores intervenientes do desmame precoce semelhantes (Quadro 1). 
Quadro 1 - Síntese dos artigos escolhidos para composição da amostra final. Salvador, BA. 2020.

\begin{tabular}{|c|c|c|c|c|}
\hline Artigo, Periódico & Autores & Objetivo & Resultados & Natureza do estudo \\
\hline $\begin{array}{l}\text { A1, Semina: Ciências } \\
\text { Biológicas e da saúde }\end{array}$ & $\begin{array}{l}\text { Barbieri MC, et al. } \\
\qquad(2015)\end{array}$ & $\begin{array}{l}\text { Observar e verificar quais informações estão sendo } \\
\text { repassadas dos profissionais de saúde para as } \\
\text { mulheres desde o período do pré-natal até o } \\
\text { puerpério. }\end{array}$ & $\begin{array}{l}\text { A maioria das orientações recebidas são durante a estadia da } \\
\text { puérpera na maternidade e nas consultas de enfermagem ao RN. } \\
\text { A amamentação exclusiva continua com baixa taxa de adesão } \\
\text { com } 37,5 \% \text {. }\end{array}$ & Quantitativa/descritiva \\
\hline $\begin{array}{l}\text { A2, Rev. Gaúcha } \\
\text { Enferm. }\end{array}$ & $\begin{array}{l}\text { Amaral LJX, et al. } \\
\qquad(2015)\end{array}$ & $\begin{array}{l}\text { Buscar os fatores que influenciam as nutrizes na } \\
\text { interrupção da amamentação exclusiva. }\end{array}$ & $\begin{array}{l}\text { Baixo conhecimento materno a respeito da importância do AM, } \\
\text { questões culturais, financeiras, dificuldades durante a } \\
\text { amamentação e intercorrências pós-parto como os principais } \\
\text { motivos do desmame. }\end{array}$ & $\begin{array}{l}\text { Descritiva, exploratória e } \\
\text { qualitativa }\end{array}$ \\
\hline $\begin{array}{l}\text { A3, Rev. Esc. } \\
\text { Enferm. USP }\end{array}$ & $\begin{array}{l}\text { Figueredo SF, et al. } \\
\qquad(2013)\end{array}$ & $\begin{array}{l}\text { Identificar qual o padrão de amamentação em } \\
\text { crianças nascidas no Hospital Amigo da Criança } \\
\text { durante seu primeiro semestre de vida. }\end{array}$ & $\begin{array}{l}\text { Com os dados analisados, é possível perceber que a prática do } \\
\text { aleitamento materno exclusivo foi diminuindo conforme o passar } \\
\text { dos meses. Sendo com } 30 \text { dias }(75 \%), 90 \text { dias }(52 \%), 120 \text { dias } \\
(33 \%), 150 \text { dias }(19 \%) \text { e } 180 \text { dias }(5,7 \%) \text {. }\end{array}$ & Descritiva/ exploratória \\
\hline A4, Esc. Anna Nery & $\begin{array}{l}\text { Demitto MO, et al. } \\
(2013)\end{array}$ & $\begin{array}{l}\text { Verificar a associação do uso de chupeta com o } \\
\text { desmame precoce, além de comparar o tempo de } \\
\text { amamentação exclusiva com o período de início do } \\
\text { uso da chupeta. }\end{array}$ & $\begin{array}{l}\text { A amostra utilizada foi com } 362 \text { crianças, onde a maioria não fazia } \\
\text { o uso de chupeta. Aquelas que utilizavam não tiveram grande } \\
\text { diferença em relação ao tempo de AME, porém foi encontrada } \\
\text { associação do uso da chupeta com o desmame precoce. }\end{array}$ & Quantitativa \\
\hline A5, Saúde em debate & $\begin{array}{l}\text { Batista KRA, et al. } \\
\qquad(2013)\end{array}$ & $\begin{array}{l}\text { Observar a prática da enfermagem e qual sua } \\
\text { relação na prevenção ao desmame precoce como } \\
\text { suporte social. }\end{array}$ & $\begin{array}{l}\text { Analisando as } 16 \text { mulheres, foi possível perceber que a maioria } \\
\text { não obteve um acompanhamento adequado da enfermagem, } \\
\text { encontrando assim mais dificuldades além da falta de informação, } \\
\text { acarretando na interrupção do aleitamento. }\end{array}$ & Exploratória e qualitativa \\
\hline $\begin{array}{l}\text { A6, Rev. Bras. Saúde } \\
\text { Mater. Infan }\end{array}$ & $\begin{array}{l}\text { Barbosa GEF, et al } \\
\qquad(2018)\end{array}$ & $\begin{array}{l}\text { Verificar quais são as primeiras dificuldades durante } \\
\text { o aleitamento materno e sua influência relacionada a } \\
\text { duração do AME. }\end{array}$ & $\begin{array}{l}\text { O estudo mostrou que intercorrências mamárias, trabalho } \\
\text { materno, e baixo nível de escolaridade são fatores que } \\
\text { ocasionam a interrupção do aleitamento. Enquanto a baixa renda } \\
\text { mostrou-se um fator protetor. }\end{array}$ & $\begin{array}{l}\text { Prospectiva, } \\
\text { observacional e analítica }\end{array}$ \\
\hline $\begin{array}{l}\text { A7, Rev. Eletr. } \\
\text { Enferm. }\end{array}$ & $\begin{array}{l}\text { Santos PV, et al } \\
\text { (2019) }\end{array}$ & $\begin{array}{l}\text { Analisar a questão do desmame precoce em } \\
\text { crianças atendidas pela ESF e sua prevalência. }\end{array}$ & $\begin{array}{l}\text { O estudo mostra que a prevalência do desmame ocorre } \\
\text { geralmente entre o primeiro e o terceiro mês de vida. Classe } \\
\text { econômica também se apresentam como fator associado ao } \\
\text { desmame precoce. }\end{array}$ & $\begin{array}{l}\text { Descritiva, quantitativa e } \\
\text { exploratória }\end{array}$ \\
\hline $\begin{array}{l}\text { A8, Rev. Enferm, } \\
\text { UFPI }\end{array}$ & $\begin{array}{l}\text { Sousa MS, et al. } \\
\qquad(2015)\end{array}$ & $\begin{array}{l}\text { Observar qual o perfil das mães que interromperam } \\
\text { o aleitamento e quais os fatores de risco para } 0 \\
\text { desmame. }\end{array}$ & $\begin{array}{l}\text { Foi evidenciado jovens mães com renda mensal menor que um } \\
\text { salário mínino, jovens, casadas e com uma média de } 10,5 \text { de } \\
\text { estudo, porém apenas uma mulher das } 56 \text { entrevistadas teve } \\
\text { licença a maternidade no período ideal ( } 6 \text { meses) e } 17 \text { relataram } \\
\text { leite insuficiente como causa para interrupção do aleitamento. }\end{array}$ & Descritiva/ quantitativa \\
\hline A9, J Pediatr (Rio J) & $\begin{array}{l}\text { Silva CS, et al. } \\
\qquad(2017)\end{array}$ & $\begin{array}{l}\text { Observar a ocorrência do aleitamento materno } \\
\text { exclusivo associada com a depressão pós-parto. }\end{array}$ & $\begin{array}{l}\text { Foi observado que das mulheres analisadas, } 50,8 \% \text { praticava } 0 \\
\text { aleitamento materno exclusivo. } 11,8 \% \text { das mães apresentavam } \\
\text { depressão pós-parto, sendo que dentre elas foi encontrada uma } \\
\text { maior chance de desmame precoce. }\end{array}$ & Corte transversal \\
\hline $\begin{array}{l}\text { A10, Rev. Enferm. } \\
\text { UFPE }\end{array}$ & $\begin{array}{l}\text { Silva AM, et al. } \\
\qquad(2018)\end{array}$ & $\begin{array}{l}\text { Analisar quais são os problemas em relação a } \\
\text { amamentação exclusiva, mais apresentados por } \\
\text { primíparas nas UBS. }\end{array}$ & $\begin{array}{l}\text { Com base na pesquisa, mostraram-se os principais problemas } \\
\text { sendo culturais (crenças), ambientes, trabalho materno, } \\
\text { ingurgitamento mamário, pega incorreta, tempo curto e agitação } \\
\text { do bebê. }\end{array}$ & $\begin{array}{l}\text { Quantitativa, exploratória } \\
\text { e descritiva }\end{array}$ \\
\hline
\end{tabular}

Fonte: Araújo SC, et al., 2021. 
Conforme demonstrado no quadro síntese, identificou-se que as maiores dificuldades que as puérperas encontram durante o período do aleitamento e os fatores intervenientes do desmame precoce são: fissuras ou ingurgitamento mamário, a pega incorreta, o retorno da mulher ao mercado de trabalho, uso de chupetas e bicos artificiais, baixo nível de escolaridade, renda, crenças, mitos e a depressão pós-parto que tem baixa incidência nas puérperas, mas altos indícios de interrupção do aleitamento materno exclusivo. Foi possível perceber a falta de orientação e de incentivo ao aleitamento materno tanto no pré-natal quanto no puerpério.

\section{DISCUSSÃO}

As crenças e mitos estão atreladas ao contexto sociocultural, pois a partir deles que são criados os sensos comuns, onde são difundidas informações sem embasamento científico que podem acabar dificultando o processo do aleitamento materno exclusivo. É evidenciado a influência dos comportamentos culturais atrelado com o baixo conhecimento a respeito dos benefícios da amamentação. Com base nos relatos, é possível perceber suas queixas a partir da crença de insuficiência do leite até o mito do leite fraco (BARBIERI MC, et al. 2015; SOUSA MS, et al., 2015; AMARAL LJX, et al., 2015).

Acreditar na insustentabilidade ou insuficiência do leite materno, é responsável por $27 \%$ das dificuldades encontradas por primíparas, e é algo muitas vezes passado de geração em geração, gerando assim a oferta de outros tipos de líquidos como chás e sucos, diminuindo o aleitamento. O medo relacionado a estética corporal influencia muitas mulheres a desistirem da prática, onde as mesmas já ouviram e acreditam que a amamentação faz os seios caírem, acabando por desenvolver medo e insegurança relacionada ao ato. Existe também a interferência de pessoas no clico familiar da puérpera, devido as experiências anteriores pautadas em crenças, influenciando diretamente na criação da puérpera ao recém-nascido, levando ao oferecimento de bicos artificiais, na alimentação precoce e na introdução de água e chás (SILVA AM, et al., 2018; PRATES LA, et al., 2014).

Existem variáveis a respeito do nível educacional, já que está atrelado muitas vezes com o nível socioeconômico. As mulheres de baixa escolaridade tendem a iniciar a introdução alimentar precoce, pois costumam desconhecer as informações básicas a respeito do AM exclusivo, do seu fator nutritivo e a importância para o suprimento das necessidades, crescimento e desenvolvimento da criança, bem desconhece a respeito dos benefícios desse aleitamento para a saúde materna. Essas gestantes também costumam a iniciar as consultas de pré-natal de maneira tardia e possuem uma menor quantidade de comparecimento às consultas, dificultando o processo de orientação e educação em saúde para promoção do materno exclusivo (BARBIERI MC, et al., 2015; SANTOS PV, et al., 2018).

A UNICEF (2019) comprova que quanto mais alta for a renda, maiores são as chances de um lactente não ser amamentado de maneira exclusiva. Em países de classe média-alta, as taxas do aleitamento são ainda mais baixas, possuindo cerca de $23,9 \%$. A realidade das mulheres com uma classe econômica baixa é de não ter um trabalho fixo, muitas vezes realizando apenas as atividades domésticas, o que também favorece o aleitamento materno, já que é encontrada uma maior facilidade para manter a livre demanda. Porém, mulheres de baixa renda mostraram manter o aleitamento materno exclusivo durante um maior período, por questões de redução de gastos, já que não há a necessidade de alimentação complementar durante 6 meses (BARBOSA GEF, et al., 2018; SILVA CS, et al., 2017).

O trabalho materno é frequentemente citado como um fator que ocasiona a interrupção do aleitamento, já que muitas mulheres relatam que Ihe faltam tempo para essa prática. Com o retorno da nutriz ao mercado de trabalho, foi possível observar que na maioria das vezes, acaba gerando uma sensação de necessidade de iniciar a introdução alimentar precocemente ou o uso de leites artificiais, além de ocasionar a ausência da estimulação das mamas que irá desencadear a diminuição considerável da produção láctea devido também a quebra do vínculo mãe e filho. Geralmente, a licença maternidade dura um período de no máximo 4 meses, levando as mulheres voltarem a suas atividades antes do período preconizado para o aleitamento materno exclusivo que é de 6 meses. Não existe apoio suficiente para genitoras sustentar uma amamentação exclusiva (BARBOSA GEF, et al., 2018; SOUSA MS, et al., 2015).

A conjuntura das mulheres trabalhadoras que atuam no mercado informal é ainda mais inconsistente, visto que, não possuem os direitos trabalhistas necessários para transpor o momento de amamentar. Uma vez 
que, as profissionais autônomas retornam ao trabalho precocemente, o que contribui para a interrupção do aleitamento materno exclusivo até os 6 meses de vida do bebê. A jornada de trabalho da genitora também tem impacto direto no aleitamento materno, pois quanto mais carga horária diária, mais difícil fica o processo de conciliação do AM nos períodos de descanso, tanto pelo fato da residência ser distante do local de trabalho, quanto pelo fato de que a maioria das empresas não possuem creches para as crianças a fim de facilitar a amamentação (RIBEIRO KV, et al., 2017; BRASILEIRO AA, et al., 2012).

As intercorrências mamárias podem ser consideradas fatores significativos para o desmame, que podem ocorrer durante a hospitalização, mas são na sua grande maioria durante o retorno ao lar. Dentre elas, são comumente citadas as fissuras mamárias que ocorrem com o posicionamento e a pega incorreta do RN, o ingurgitamento mamário devido ao acúmulo e falta de fluxo do leite e a mastite que é um processo inflamatório podendo ser infeccioso, mas quando não infeccioso também pode ser causado devido ao acúmulo do leite nos ductos (SILVA AM, et al., 2018).

A pega incorreta pode ser desencadeada pela falta de instrução, principalmente no cuidado especial com as puérperas ou gestantes que possuem mamilos planos ou invertidos por desenvolverem maior dificuldade. Essas intercorrências ocorrem pela ausência de acompanhamento e orientações, gerando uma rejeição a amamentação, pois as queixas são de dores intensas, sangramentos nos mamilos antes, durante e após a mamada e dificuldade em corrigir a pega principalmente por primíparas, portanto, a saída mais fácil tomada é o abandono do aleitamento devido ao medo e a insegurança (BARBOSA GEF, et al., 2018; SOUSA MS, et al., 2015; SILVA CS, et al., 2017).

A Sociedade Brasileira de Pediatria (2017), diz que uso de chupetas ou de bicos artificiais não são recomendados, pois são danosos a saúde da criança, dificultando o processo de mastigação, sucção e deglutição, além de prejudicar a prolongação do aleitamento. Apesar da maioria das crianças não fazerem o uso de chupeta, a porcentagem que utiliza tem cerca de 3,2 vezes mais chances de interromperem o AME. Foi possível observar que o uso da chupeta também interfere significativamente no vínculo mãe e filho, por diminuir as frequências das mamadas, mas também que o seu oferecimento pode estar atrelado a insegurança e a ansiedade materna (DEMITTO MO, et al., 2013).

Também foi evidenciado que diversas vezes a introdução da mamadeira juntamente com leites artificiais foram orientados por profissionais de saúde, como por exemplo pediatras, para complementar a alimentação em bebês com menos de seis meses. Os argumentos a favor da chupeta são que seu oferecimento é única coisa que acalenta e consola a criança nos momentos de desespero e exaustão materna, pois diminui a agitação do bebê e a frequência dos episódios de choro (SOUSA MS, et al., 2015; SANTOS PV, et al., 2018; SOCIEDADE BRASILEIRA DE PEDIATRIA, 2017).

A depressão pós-parto é um fator psicológico que pode vir a ser desenvolvido por algumas mulheres no período do puerpério. Mulheres que vivenciam a depressão puerperal tendem a ter menos confiança, disposição, ter dificuldade no contato com a criança para estabelecimento do vínculo ou falta de afeto, aumento no estresse, medo e tristeza, que consequentemente irá levar a dificuldade de amamentar, tendendo a interromper o AME precocemente (OLIVEIRA MG, et al., 2019)

Um estudo mostrou que uma pequena parcela de $11,8 \%$ das mulheres entrevistadas desenvolveu a depressão pós-parto (DPP), porém, essas que possuíam os sintomas tenderam a mostrar cerca de 1,63 mais chances de interromper o aleitamento materno exclusivo logo nos primeiros meses de vida da criança. Esses sintomas depressivos podem ser associados a autoeficiência da amamentação, já que a autoconfiança materna influencia a permanência na prática, a ausência desse sentimento devido a condição da puérpera, tende a ocasionar o desame precoce. Portanto, é necessário o diagnóstico precoce da doença em questão, para evitar os danos a curto e longo prazo. Dessa forma, fica clara a importância do acompanhamento multidisciplinar durante todo o período gestacional e puerperal, pois um acompanhamento pode promover o desenvolvimento saudável da díade mãe-bebê, aumentando assim as taxas de AME (SILVA CS, et al., 2017).

Existe uma dificuldade em se adaptar à nova vida, devido as mudanças fisiológicas como as hormonais e físicas, além das psicológicas e sociais. Almeja-se que essa relação seja desenvolvida em um contexto benéfico e conveniente para ambos, porém o sentimento de obrigação da amamentação tem predominância 
nas mulheres que vivenciaram esse problema, gera aversão a prática e a sua desistência. Contudo, a depressão pós-parto pode transformar essa experiência em desagradável e até mesmo prejudicial, trazendo repercussões diretas para o desenvolvimento infantil (OLIVEIRA MG, et al., 2019).

A enfermagem tem um importante papel para redução das taxas de desmame precoce, garantindo a prática adequada da amamentação e incentivando o $\mathrm{AME}$, porém, muitas mulheres relatam não serem orientadas durante a gestação ou até mesmo após, por isso a enfermagem deve atuar na prevenção do desmame desde o pré-natal até o puerpério, não só nas maternidades, mas também em visitas domiciliares. As orientações são-ofertadas em sua grande maioria, durante a estadia da mulher na maternidade, durante as consultas e enfermagem e no pré-natal (BATISTA KRA, et al., 2013; DEMITTO MO, et al., 2013; BARBIERI MC, et al., 2015).

Para isso, é importante que haja a capacitação e a educação permanente dos profissionais, pois eles devem intervir de maneira positiva, para que assim sejam encontradas estratégias que auxiliem nos problemas encontrados pelas mulheres durante o período de amamentação. As orientações que protegem as puérperas do desmame precoce envolve a explanação sobre os benefícios do aleitamento, como prevenir e intervir a respeito das possíveis complicações, como realizar o posicionamento do bebê para realização da pega correta para que haja preensão e sucção eficaz, explicar como funciona os direitos frente a licença maternidade, desmistificação de crenças, encorajamento da amamentação e sanar todas as dúvidas (FONSECA-MACHADO MO, et al., 2012; SOUSA MS, et al., 2015).

Um estudo realizado em um Hospital Amigo da Criança, aponta que as orientações fornecidas pela enfermagem, juntamente com recomendações e estímulos constantes ao AM, fazem essas puérperas façam a manutenção do mesmo. Dessa forma, ratifica-se a relevância das orientações fornecidas às mulheres durante o período gravídico puerperal (FIGUEREDO SF, et al., 2013).

\section{CONSIDERAÇÕES FINAIS}

O desmame precoce perpetua-se como um problema de saúde pública, uma vez que, as puérperas vivenciam e sofrem com os fatores e as dificuldades que interferem no aleitamento. A prática não é simploriamente instintiva, a realidade também gira em torno de medos, inseguranças e intercorrências. Foi possível observar falhas nas orientações durante a assistência, desde o pré-natal até o puerpério. Portanto, constata-se a necessidade de um acompanhamento de enfermagem contínuo mesmo após a saída da puérpera da maternidade, pois através da continuidade do cuidado, nas consultas de crescimento e desenvolvimento na atenção básica é possível ofertar orientações de promoção ao aleitamento materno exclusivo e assim reduzir as taxas de desmame precoce.

\section{REFERÊNCIAS}

1. AMARAL LJX, et al. Fatores que influenciam na interrupção do aleitamento materno exclusivo em nutrizes. Rev Gaúcha Enferm., 2015; 36(esp): 127-34.

2. BARBIERI MC, et al. Aleitamento materno: orientações recebidas no pré-natal, parto e puerpério. Semina: Ciências Biológicas e da Saúde. 2015; 36(1): 17-24.

3. BARBOSA GEF, et al. Dificuldades iniciais com a técnica da mamada e o impacto na duração do aleitamento materno exclusivo. Rev. Bras. Saúde Mater. Infan., 2018; 18(3): 517-526.

4. BARDIN L. Análise de Conteúdo. Lisboa; LDA, 2016.

5. BATISTA KRA, et al. Influência da assistência da enfermagem na prática da amamentação no puerpério imediato. Saúde em Debate, 2013; 37(96): 130-8.

6. BOTELHO LLR, et al. O método da revisão integrativa nos estudos organizacionais. GeS, 2011; 5(11): $121-36$.

7. BRASILEIRO AA, et al. Amamentação entre filhos de mulheres trabalhadoras. Rev Saúde Pública, 2012; 46(4): 64248.

8. BRASIL. Ministério da Saúde. Secretaria de Atenção à Saúde. Bases para a discussão da Política Nacional de Promoção, Proteção e Apoio ao Aleitamento Materno. 1 ed. Brasília: MS, 2017.

9. BRASIL. Ministério da Saúde. Secretaria de Políticas Públicas de Saúde. Saúde da Criança: Aleitamento Materno e Alimentação Complementar. 2 ed., n. 23. Brasília: MS, 2015.

10. DEMITTO MO, et al. Uso de chupeta e aleitamento materno exclusivo. Escola Anna Nery Revista de Enfermagem, 2013; 7(2): 271-6.

11. FIGUEREDO SF, et al. Hospital Amigo da Criança: prevalência de aleitamento materno exclusivo aos seis meses e fatores intervenientes. Rev. Esc. Enferm. USP, 2013; 47(6): 1291-7. 
12. FLORINDO AKF, et al. O papel do enfermeiro no desmame precoce, 2018; 8(4): 27-13.

13. FONSECA-MACHADO MO, et al. Aleitamento materno: conhecimento e prática. Revista da Escola de Enfermagem da USP, 2012; 46(4): 806-15.

14. MARTINS MZO, SANTANA LS. Benefícios do aleitamento para saúde materna. Interfaces Científicas - Saúde e Ambiente, 2013; 1(3): 87-97.

15. MONTESCHIO CAC, et al. O enfermeiro frente ao desmame precoce na consulta de enfermagem à criança. Revista Brasileira de Enfermagem, 2015; 68(5): 869-875.

16. OLIVEIRA CS, et al. Amamentação e as intercorrências que contribuem para o desmame precoce. Rev Gaúcha Enferm., 2015; 36(esp): 16-23.

17. OLIVEIRA MG, et al. Sentimento de mulheres com depressão pós-parto frente ao aleitamento materno. Enferm. Foco, 2019; 10(3): 88-92.

18. ORGANIZAÇÃO PAN-AMERICANA DA SAÚDE. Aleitamento materno nos primeiros anos de vida salvaria mais de 820 mil crianças menores de cinco anos em todo o mundo. Brasília, DF; 2017. Disponível em: https://www.paho.org/bra/index.php?option=com_content\&view=article\&id=5729:aleitamento-materno-nos-primeirosanos-de-vida-salvaria-mais-de-820-mil-criancas-menores-de-cinco-anos-em-todo-omundo\&Itemid=820\#: :text=Em\%20abril\%20deste\%20ano\%2C\%20a,cinco\%20anos\%20todos\%20os\%20anos. Acesso em 15 dez 2020.

19. PRATES LA, et al. Amamentação: A influência familiar e o papel dos profissionais de saúde. Revista de Enfermagem da UFSM, 2014; 4(2):359-367.

20. RIBEIRO KV, et al. A amamentação e o trabalho informal: a vivência de mães trabalhadoras. Revista Pró-univerSUS, 2017; 08(2): 03-09.

21. SANTOS PV, et al. Desmame precoce em crianças atendidas na Estratégia de Saúde da Família. Revista eletrônica de Enfermagem, 2018; 20(1): 1-12.

22. SILVA ACR, et al. Desmame precoce: uma revisão sistemática. Revista Eletrônica Acervo Saúde, 2019; 30(1013): 110.

23. SILVA AM, et al. Aleitamento materno exclusivo: empecilhos apresentados por primíparas. Revista de Enfermagem da UFPE, 2018; 12(12): 3205-3211.

24. SILVA CS, et al. Association between postpartum depression and the practice of exclusive breastfeeding in the first three months of life. J Pediatr (Rio J), 2017; 93(4): 356-364.

25. SOCIEDADE BRASILEIRA DE PEDIATRIA. Uso de chupeta em crianças amamentadas: prós e contras. Departamento Científico de Aleitamento Materno, 2017; (3): 1-16.

26. SOUSA LMM, et al. A metodologia de revisão integrativa da literatura em enfermagem. Revista investigação em enfermagem, 2017; 17-26.

27. SOUSA MS, et al. Aleitamento materno e os determinantes do desmame precoce. Revista de Enfermagem da UFPI, 2015; 4(1): 19-25.

28. UNICEF BRASIL. Porque as políticas em prol das famílias são fundamentais para aumentar as taxas de amamentação em todo o mundo. 2019. Disponível em: https://www.unicef.org/brazil/comunicados-de-imprensa/por-que-politicas-emprol-das-fam\%C3\%ADlias-sao-fundamentais-para-aumentar-taxas-de-amamentacao 